\title{
Factor Structure of the Ruminative Response Scale and Measurement Invariance across Gender and Age among Chinese Adolescents
}

\author{
Lijuan Liang1, Yung-Hsing Lee ${ }^{2^{*}}$ \\ ${ }^{1}$ Department of Psychology, Hainan Medical University, Haikou, China \\ ${ }^{2}$ Medical Psychological Institute, Hainan Health Management College, Haikou, China \\ Email: ^523361270@qq.com
}

How to cite this paper: Liang, L. J., \& Lee, Y.-H. (2019). Factor Structure of the Ruminative Response Scale and Measurement Invariance across Gender and Age among Chinese Adolescents. Advances in Applied Sociology, 9, 193-207. https://doi.org/10.4236/aasoci.2019.96016

Received: May 7, 2019

Accepted: June 16, 2019

Published: June 19, 2019

Copyright () 2019 by author(s) and Scientific Research Publishing Inc. This work is licensed under the Creative Commons Attribution International License (CC BY 4.0).

http://creativecommons.org/licenses/by/4.0/ (c) (i) Open Access

\begin{abstract}
Methods: Participants included 1103 adolescents from Hunan Province and Hainan Province in China. A confirmatory factor analysis (CFA) was conducted to determine the structure of the RRS on a large scale. Multiple CFAs were utilized to test the measurement invariance of the three subscales included in the RRS, across gender and age. Results: The RRS exhibited strong internal consistency (overall Cronbach's alpha coefficient $=0.927$ ) and internal reliability $(0.362-0.864)$. The CFA showed a valid three-factor model. Measurement invariance of the model across gender and age was fully supported. Conclusions: Total RRS and subscales have accepted validity and reliability. Three-factor model of the RRS across gender and age was established. Measurement equivalence of the RRS across gender and age was established among Chinese adolescents. These findings suggest that the use of the RRS in comparing samples across gender and age is valid.
\end{abstract}

\section{Keywords}

Ruminative Response Scale, Factor Structure, Measurement Invariance, Gender and Age, Chinese Adolescents

\section{Introduction}

The Ruminative Response Scale (RRS) is frequently used self-report measure of depressive rumination in both research and clinical practice to assess the severity of depressive rumination. The current study evaluated the best-fit factor structure model of the Chinese version of the RRS among Chinese adolescents and evaluated the measurement invariance of the RRS across gender and age. 
Adolescence is a special period in depression researches. With the increasing incidence of depression from childhood, adolescence is the main transitional period from childhood to adulthood. Therefore, the study of adolescent depression is of great significance. Previous researches have shown that the first episode of depression in individuals usually occurs between the ages of 14 and 19, and the prevalence of lifelong depression is as high as $25 \%$ at the end of adolescence (Kessler et al., 2001).

According to the cognitive model of depression, depression is caused by negative cognitive diagrams, so patients tend to choose negative information consistent with their own negative schema (Abramson et al., 1989). Rumination is a sensitive factor in the pathogenesis of depression and plays an important role in the generation and maintenance of depression (Thomsen et al., 2011). Research has showed the development of depression was associated with the rumination which is a risk factor for adolescence (Kelsey et al., 2017; Thomsen et al., 2013; McMurrich \& Johnson, 2008). Further researches even showed that rumination wasn't only correlated with the symptoms of depression, but also could predict the onset of depressive disorders at each subsequent assessment, even over the subsequent year (Broderick \& Korteland, 2004; Wilkinson et al., 2013).

According to the response styles theory (Nolen-Hoecksema et al., 1992), the gender difference of depression is discussed from the point of view of the cognitive strategy of the negative emotion, and the response styles were proposed: the brooding, the distraction and the problem solving. The brooding is the negative reaction style, and the distraction and the problem solving are the positive response styles (Dickson et al., 2017). As compared to boys, girls tend to be more likely to apply to the negative reaction style, so they are more likely to be depressed (Nolen-Hoecksema, 1987, 1991). Gender was investigated as a moderator which moderated the relation among brooding, reflection and depression symptoms (LeMoult et al., 2019). Related researches found that female adolescents reported more engagement in brooding rumination than male adolescent (Jos \& Weir, 2013; Hamlat et al., 2015). Furthermore, the rumination was related to more concurrent and prospective depressive symptoms in girls, but reflection predicted less concurrent and prospective depressive symptoms in girls (Bastin et al., 2018, Paredes \& Zumalde, 2015). Compared with males, related researches indicated that girls with more generalized autobiographical memories in combination with higher levels of rumination were most vulnerable to experiencing increases in depressive symptoms following stressful life events (Connolly et al., 2015). On the other hand, some researches found no differences were observed in gender on depression or rumination (Broderick \& Korteland, 2004). Performance factorial invariance across ages is necessary to determine gender differences on the ruminative response scale (RRS).

Adolescence is a special period, with the significantly physical and psychological changes. At the same time, due to the non-synchronization of the physiological maturity and the mental maturity, the young people can be easily ab- 
sorbed into the brooding, the depression, and so on. The total scores and subscales of the RRS may change with age as adolescents develop. Some longitudinal studies indicated that there was no statistically significant difference between two time points (Schoofs et al., 2010). While many studies have utilized the related scales to assess the effect of intervention and treatment (Wilkinson \& Goodyer, 2008, Campbell et al., 2012), and therefore the time equivalence of the RRS has significance and value.

Two main versions of the RRS have been proposed, which differ in terms of item composition. The first report of RRS was put forward by Nolen-Hoeksema and Morrow (Nolen-Hoeksema, 1991) selected a priori 22 items for the RRS. In subsequent studies, Butler and Nolen-Hoeksema (Butler \& Nolen-Hoeksema, 1994) used a two-factor version with 10 items. So more researches discussed the reliability and validity of the two factors of RRS (Hasegawa, 2013; Lei et al., 2017; Lucena-Santos et al., 2018), but less researches focused on the reliability and validity of the three factors. The RRS has emerged as the most frequently used self-report measure of depressive rumination in both researches and clinical practice for its wide target population and stable reliability and validity in Japanese, Dutch and Korean (Topper et al., 2014; Shin, Cho, \& Kim, 2015). Researches about university students of Chinese had shown that the CFA about the two factors of RRS exceptive of depression fit the model and the measurement equivalence of the RRS-10 was acceptable across gender. Otherwise some related research also performed three factors of RRS to evaluate the depression, the rumination and the reflection (Stringars \& Goodman, 2013; Treynor et al., 2003). So it is necessary to assess the three factor model of RRS.

The main aims of the research were to examine the factor structure of the 22-item RRS in Chinese adolescents, and to test the measurement invariance of the 22-item RRS across gender and age. The effective use of any scale is dependent on the measurement indices of the scale, and as such, the equivalence test is critical. True inter-group differences cannot be determined when there is measurement invariance (Stringars \& Goodman, 2013).

\section{Material and Methods}

\subsection{Participants}

A total sample of 1134 students completed the RRS questionnaire. Age of participants ranged from 13 to 18 years $(M=16.02 ; S D=0.849)$. Students from both urban and rural areas accounted for $41.8 \%$ and $58.2 \%$ respectively. Due to the small sample size of 13 year-olds $(n=8)$ and 18 year-olds $(n=15)$, these two ages were excluded from the analysis of age equivalence. Cases with missing data on gender, age, or RRS items were excluded. The final sample was comprised of 1102 adolescents (535 males and 567 females).

\subsection{Procedure}

The research was approved by the Ethics Committee of the Second Xiangya 
Hospital, Central South University and Hainan Medical University. Participation was voluntary and signed parental informed consent was necessary to participate. All questionnaires were administered in the classroom, in the form of pen and paper. The questionnaire took approximately 40 minutes to complete. The questionnaire was administered at different times to at least four subjects at each session. The teacher of the class was present to ensure that the students cooperated.

\subsection{Instruments}

The Ruminative Response Scale (RRS) is a self-report questionnaire, which includes 22 items describing responses to depressed mood which distributed across three subscales: depression, brooding and reflection (Treynor et al., 2003). Responses can be acting or thinking about the depressive symptoms and thinking about possible causes and consequences of the sad/depressed mood. Each item are rated on a 4 -point Likert scale ranging from 1 (never) to 4 (always). The total score ranges from 22 to 88, with higher scores indicating higher degrees of ruminative symptoms. The Brooding of the RRS assesses a maladaptive aspect of rumination, whereas the Reflection assesses an adaptive or relatively less maladaptive aspect of rumination,

The Chinese version RRS was developed through forward and back translation by separate bilingual translators. No questionnaire item was removed or altered significantly during translation.

\subsection{Data Analyses}

Epidata was used for data entry. SPSS and AMOS were used for data analysis. Due to the equilibrium of age distribution, normal tests were performed on every item. Descriptive analyses were performed in SPSS, V23.

A confirmatory factor analysis (CFA) was performed to assess the relationship between the three subscales. Model fit was assessed with various fit indices, including a robust $\chi^{2}$ with estimated degrees of freedom (df), a comparative fit index (CFI), and a root mean squared error of approximation (RMSEA).

The reliability of the RRS was estimated with Cronbach's alpha, and a correlation analysis on the scores total and the three subscales. On the basis of Cronbach's alpha $>0.5$, further analyses of construct reliability $(\mathrm{CR})$ and average variance extracted (AVE) were performed.

After identification of the best fitting RRS model and considerable reliability, measurement invariance tests were conducted across gender and age for the effectiveness of inter-group comparisons. Five aspects of invariance were considered. Model 1: configural invariance tested the structure of latent variables across groups; Model 2: factor loading invariance based on Model 1 was constrained to be equal across gender; Model 3: scalar invariance based on the metric invariance results with variable intercepts constrained to equality; Model 4: factor covariance invariance was tested which verified equality of the covariance 
between groups; and Model 5: a test of strong equivalence was performed, that is, residual error invariance with error variance was set as equal. The CFI and the Tucker Lewis Index (TLI) were used to evaluate invariance across consecutive models; CFI and TLI were more than 0.9, measurement invariance was accepted; a $\Delta \mathrm{CFI} \leq 0.01$ with a $\Delta \mathrm{TLI} \leq 0.01$ was considered evidence of invariance, as suggested by Cheung and Rensvold (Cheung \& Rensvold, 2002).

\section{Results}

\subsection{Normal Distribution Test}

From the analysis results of the Table 1, it can be seen that the mean distribution of each item in the measurement variable is more balanced. The absolute value of skew coefficient of each item is 1.290 , which is far less than the standard value of 3 , and the absolute value of kurtosis coefficient is 1.147 , which is much smaller than the standard value of 8 (Kline, 2005). It means that the data of each item approximately conform to the normal distribution. The maximum likelihood method (ML) can be used to model the CFA and the structural equation.

\subsection{CFA}

The three factors accounted accumulatively for $58.28 \%$ of the total variance. Item loadings are reported in Figure 1. The standardized factor loadings of the three-facet model are presented in Figure 1. The factor loadings of all items were greater than 0.4, except RRQ12 (Write down what you are thinking and analyze it.) of depression, item 13 (Think about a recent situation, wishing it had gone better) of brooding and item 14 (Think "I won't be able to concentrate if I keep feeling this way.") of the brooding subscale (0.36). Therefore, all items of three-factor model for the Chinese version RRS didn't meet the criterion (Cheung \& Rensvold, 2002). But after effect modification by cut-off the low factor loading item, the CFA revealed an moderate to good fit according to the CFI, GFI,TLI and RMSEA (0.916, 0.906, 0.872 and 0.062, respectively) (Table 2).

\subsection{Reliability and Validlity}

The Cronbach's alpha of the total score and each subscale were greater than 0.5 and inter-subscale correlations of the total score and each subscale ranged from 0.362 to 0.864 (Table 3). To further verify the reliability of the RRS, we performed Construct Reliability (CR) and Average Variance Extracted (AVE), the results are shown in Table 3 . The CRs of all subscales were greater than 0.6 , and all AVEs were relatively lower which indicates that the latent variable has good Better combination reliability but limited convergence validity (Fornell \& Larcker, 1981; Tsaousis \& Kazi, 2013).

\subsection{Factorial Invariance across Gender}

Multiple-group analysis was performed to examine the cross-gender structural 
equivalence of the RRS. In addition, the model served as a baseline for the proceeding analysis. The following fit indices were obtained: TLI $=0.873, \mathrm{CFI}=$ $0.917, \mathrm{GFI}=0.932$, RMSEA $(90 \% \mathrm{CI})=0.043(0.038,0.049)$ respectively. Each fit index (see Table 4) met the requirements for configural invariance (Table 4).

Based on the configural invariance, equivalent factor loads were set to verify that each item represented the same concept across gender. Compared to the baseline Model 1 (as reported above), $\chi^{2}$ increased to 24.20, reaching significance. However, because the significance of $\chi^{2}$ is easily affected by sample size, we assessed the other fit indices (Cheung \& Rensvold, 2002; Johnson et al., 2008). According to the equivalence test (see Table 4), both of the $\Delta$ CFI and the $\Delta$ TLI were 0.002 , less than 0.01 (Cheung \& Rensvold, 2002). These results indicated that factor loading invariance was established, indicating weak equivalence.

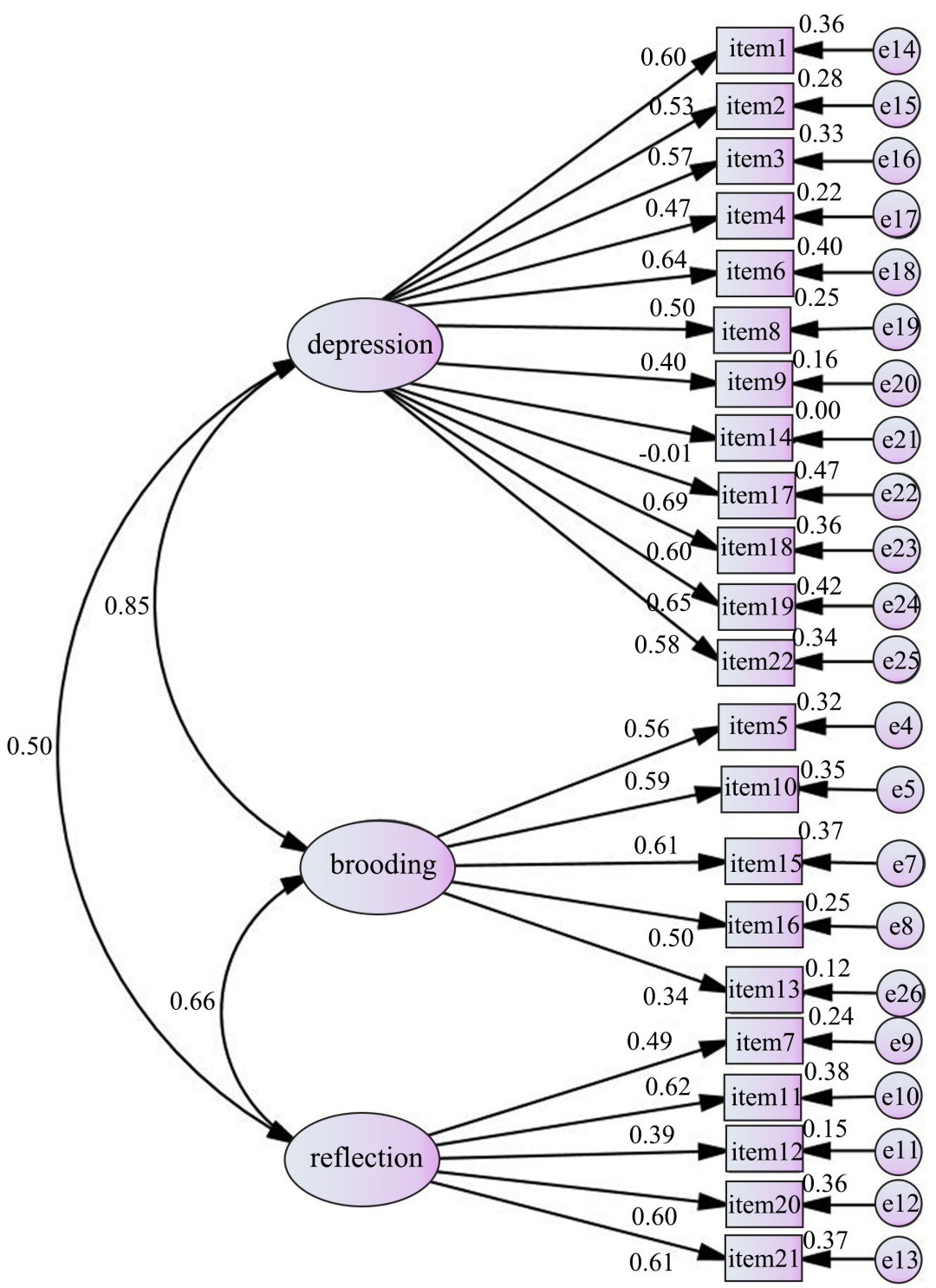

Figure 1. Three-factor structural model of chinese-ruminative response scale. 
Table 1. Descriptive statistical results for each item of the RRS.

\begin{tabular}{|c|c|c|c|c|}
\hline Item content & Mean & SD & skew & kurtosis \\
\hline 1) Think about how alone you feel & 2.05 & 0.709 & 0.774 & 1.147 \\
\hline $\begin{array}{l}\text { 2) Think "I won't be able to do my job if I don't snap out } \\
\text { of this" }\end{array}$ & 2.09 & 0.677 & 0.609 & 0.928 \\
\hline 3) Think about your feelings of fatigue and achiness. & 1.87 & 0.754 & 0.740 & 0.534 \\
\hline 4) Think about how hard it is to concentrate. & 2.29 & 0.816 & 0.373 & -0.277 \\
\hline 6) Think about how passive and unmotivated you feel. & 1.91 & 0.876 & 0.781 & -0.033 \\
\hline $\begin{array}{l}\text { 8) Think about how you don't seem to feel anything } \\
\text { anymore. }\end{array}$ & 1.78 & 0.831 & 0.906 & 0.218 \\
\hline 9) Think "Why can't I get going?" & 2.12 & 0.901 & 0.473 & -0.520 \\
\hline $\begin{array}{l}\text { 14) Think "I won't be able to concentrate if I keep feeling } \\
\text { this way." }\end{array}$ & 2.53 & 0.902 & -0.062 & -0.769 \\
\hline 17) Think about how sad you feel. & 1.89 & 0.849 & 0.746 & -0.025 \\
\hline $\begin{array}{l}\text { 18) Think about all your shortcomings, failings, faults, } \\
\text { mistakes. }\end{array}$ & 2.25 & 0.830 & 0.407 & -0.284 \\
\hline 19) Think about how you don't feel up to doing anything. & 2.00 & 0.857 & 0.662 & -0.085 \\
\hline 22) Think about how angry you are with yourself & 1.61 & 0.812 & 1.290 & 1.139 \\
\hline 5) Think "What am I doing to deserve this?" & 1.71 & 0.826 & 1.083 & 0.688 \\
\hline 10) Think "Why do I always react this way?" & 2.17 & 0.862 & 0.395 & -0.449 \\
\hline 13) Think about a recent situation, wishing it had gone better & 2.45 & 0.864 & 0.073 & -0.650 \\
\hline $\begin{array}{l}\text { 15) Think "Why do I have problems other people don't } \\
\text { have?" }\end{array}$ & 2.14 & 0.871 & 0.516 & -0.314 \\
\hline 16) Think "Why can’t I handle things better?" & 2.60 & 0.840 & 0.065 & -0.649 \\
\hline $\begin{array}{l}\text { 7) Analyze recent events to try to understand why you are } \\
\text { depressed. }\end{array}$ & 2.15 & 0.835 & 0.378 & -0.395 \\
\hline $\begin{array}{l}\text { 11) Go away by yourself and think about why you feel this } \\
\text { way }\end{array}$ & 2.20 & 0.885 & 0.405 & -0.472 \\
\hline 12) Write down what you are thinking and analyze it. & 1.80 & 0.878 & 0.898 & 0.008 \\
\hline $\begin{array}{l}\text { 20) Analyze your personality to try to understand why you } \\
\text { are depressed. }\end{array}$ & 2.08 & 0.864 & 0.528 & -0.315 \\
\hline 21) Go someplace alone to think about your feelings & 2.17 & 0.935 & 0.473 & -0.613 \\
\hline Brooding & 11.0499 & 2.73185 & 0.369 & 0.196 \\
\hline Reflection & 10.3835 & 2.90140 & 0.405 & -0.022 \\
\hline Depression & 24.3781 & 5.53141 & 0.667 & 0.925 \\
\hline Total Scores & 45.8114 & 9.20412 & 0.489 & 0.850 \\
\hline
\end{tabular}

Table 2. Goodness-of-fit Indices for RRS model:confirmatory factor analysis ( $\mathrm{N}=1074)$.

\begin{tabular}{cccccccccc}
\hline Goodness-of-fit Indices & $\chi^{2}$ & $\mathrm{df}$ & $\chi^{2} / \mathrm{df}$ & RMSEA & LO90 & HI90 & TLI & CFI & GFI \\
\hline $\begin{array}{c}\text { RRQ three } \\
\text { factors model }\end{array}$ & 357.432 & 62 & 5.765 & 0.064 & 0.060 & 0.073 & 0.839 & 0.890 & 0.867 \\
$\begin{array}{c}\text { Adjusted RRQ } \\
\text { three factors model }\end{array}$ & 199.925 & 41 & 4.876 & 0.060 & 0.052 & 0.069 & 0.890 & 0.932 & 0.914 \\
\hline
\end{tabular}


Table 3. Cronbach's alpha $(\mathrm{N}=1102)$ and inter-subscale correlations; construct reliability (CR) and average variance extracted (AVE) of three subscales.

\begin{tabular}{ccccccc}
\hline \multicolumn{7}{c}{ Inter-subscale correlations } \\
\hline RRS scale & Cronbach's alpha & 2 & 3 & 4 & CR & AVE \\
Depression & 0.797 & $0.638^{* *}$ & $0.362^{* *}$ & $0.791^{* *}$ & 0.693 & 0.430 \\
Brooding & 0.626 & & $0.468^{* *}$ & $0.864^{* *}$ & 0.659 & 0.328 \\
Reflection & 0.673 & & & $0.778^{* *}$ & 0.671 & 0.339 \\
Total scale & 0.881 & & & & \\
\hline
\end{tabular}

RRS = Ruminative Response Scale of Chinese version; ${ }^{* *} p<0.01$

Table 4. Goodness-of-fit indices and model comparisons for measurement invariance models of gender.

\begin{tabular}{|c|c|c|c|c|c|c|c|c|}
\hline Model & $\chi^{2}(\mathrm{df})$ & $\chi^{2} / \mathrm{df}$ & RMSEA $(90 \% \mathrm{CI})$ & CFI & GFI & TLI & $\Delta \mathrm{CFI}$ & $\Delta \mathrm{GFI}$ \\
\hline Unconstrained & $311.185(102)^{* * *}$ & 3.051 & $0.043(0.038-0.049)$ & 0.917 & 0.932 & 0.873 & & \\
\hline $\begin{array}{c}\text { Measurement } \\
\text { weights }\end{array}$ & $314.016(111)^{* * *}$ & 2.829 & $0.041(0.036-0.046)$ & 0.919 & 0.930 & 0.886 & 0.002 & 0.002 \\
\hline $\begin{array}{l}\text { Measurement } \\
\text { intercepts }\end{array}$ & $322.725(123)^{* * *}$ & 2.713 & $0.039(0.034-0.045)$ & 0.916 & 0.927 & 0.894 & 0.003 & 0.003 \\
\hline $\begin{array}{c}\text { Structural } \\
\text { covariances }\end{array}$ & $342.238(129)^{* * *}$ & 2.653 & $0.039(0.034-0.044)$ & 0.915 & 0.923 & 0.897 & 0.001 & 0.004 \\
\hline $\begin{array}{l}\text { Measurement } \\
\text { residuals }\end{array}$ & $366.747(141)^{* * *}$ & 2.601 & $0.038(0.033-0.043)$ & 0.910 & 0.921 & 0.901 & 0.005 & 0.002 \\
\hline
\end{tabular}

${ }^{* * *} p<0.001$.

The results of the measurement intercepts model showed that intercept equivalence was established, as both $\Delta \mathrm{CFI}$ and $\Delta \mathrm{TLI}$ were less than 0.01 (See Table 4). Based on the previous model, we tested the structural covariance invariance. The fit indices of model 4 (See Table 4) found $\Delta$ CFI and $\Delta$ TLI equal to 0.002 and 0.000 , respectively. Finally, compared with the previous models, the fit index of measurement residual invariance decreased, but the fit indices of measurement residuals invariance were good $(\mathrm{TLI}=0.901, \mathrm{CFI}=0.910, \mathrm{GFI}=0.921$, RMSEA $=0.049)$, and the $\triangle \mathrm{CFI}$ and $\Delta \mathrm{TLI}$ were less than 0.01 . The result supported that the strong equivalence also was accepted.

\subsection{Factorial Invariance across Age}

Multiple-group analysis was used to examine age equivalence of the RRS. All fit indices are listed in Table 5. All five models had good fit. The CFIs of all five examined models were approximately 0.9 and the $\Delta$ CFI was 0.000 . In addition, the TLIs and $\Delta$ TLIs were approximately 0.9 and less than 0.01 , respectively, indicating good fit.

In summary, the reliability and validity of RRS meet the measurement requirements, and the result also be in accordance with the equivalence of gender and age. 
Table 5. Goodness-of-fit indices and model comparisons for measurement invariance models of age.

\begin{tabular}{|c|c|c|c|c|c|c|c|c|}
\hline Model & $\chi^{2}(\mathrm{df})$ & $\chi^{2} / \mathrm{df}$ & RMSEA (90\%CI) & CFI & GFI & TLI & $\Delta \mathrm{CFI}$ & $\Delta \mathrm{GFI}$ \\
\hline Unconstrained & $323.290(153)$ & 2.113 & $0.044(0.037-0.050)$ & 0.902 & 0.918 & 0.873 & & \\
\hline $\begin{array}{l}\text { Measurement } \\
\text { weights }\end{array}$ & $347.490(171)$ & 2.032 & $0.042(0.036-0.048)$ & 0.898 & 0.912 & 0.882 & 0.004 & 0.006 \\
\hline $\begin{array}{c}\text { Measurement } \\
\text { intercepts }\end{array}$ & $351.378(176)$ & 1.996 & $0.41(0.35-0.47)$ & 0.897 & 0.910 & 0.887 & 0.001 & 0.002 \\
\hline $\begin{array}{l}\text { Structural } \\
\text { covariances }\end{array}$ & $356.447(183)$ & 1.948 & $0.040(0.034-0.046)$ & 0.900 & 0.911 & 0.891 & 0.002 & 0.001 \\
\hline $\begin{array}{l}\text { Measurement } \\
\text { residuals }\end{array}$ & $386.961(207)$ & 1.869 & $0.039(0.033-0.044)$ & 0.896 & 0.907 & 0.900 & 0.004 & 0.004 \\
\hline
\end{tabular}

\section{Discussion}

The data of this research are consistent with normal distribution, and the mean is relatively stable. The exploratory factor analysis of Korean sample of the two-factor RRS demonstrated some different findings in details that the item 16 (Think “Why can't I handle things better?") and item 7 (Analyze recent events to try to understand why you are depressed.) were excluded from each subordinate factor (Lee \& Kim, 2014). Even the three-factor structural model of Korean-RRS also was different from previous model that depression included 9 items, reflection included 6 items and brooding included 7 items (Shin, Cho, \& Kim, 2015). This research also showed that the factor loadings of item 14 was only -0.01 . This difference may be due to the result of different culture. Chinese-RRS of item 14 (Think "I won't be able to concentrate if I keep feeling this way.") may be excluded from depression, because Chinese may explain this item as focusing on doing something instead of indulging in these feelings. Cultural differences in language translation and understanding may account for these discrepancies.

Compared with college students (Lei et al., 2017), the middle school students' academic pressure is relatively greater, which may be related with the immature mental characteristics and the lack of self-adjustment of adolescents. This result also is consistent with the clinical results (Gotham et al., 2018) and associated with the difficulties of social maladjustment, affective recognition, emotion regulation, even suicidal ideation (Sarkisian et al., 2019; Aker, Harmer, \& Landrø, 2014).

The results of CFA showed that the structural validity of three factors model of the RRS was acceptable, and most of the factor loading was greater than 0.4, therefore most items on the RRS effectively represent latent variables. However, the item 13 (Think about a recent situation, wishing it had gone better) in the brooding subscale (0.34) and the item 12 (Write down what you are thinking and analyze it) in the reflection subscale (0.39) were not satisfactory. These results was similar with the previous researches of Dutch (Schoofs et al., 2010; Treynor et al., 2003) and other Asian countries (Shin et al., 2015). Previous re- 
searches concerning RRS-10's factor analysis have shown a good two-factor structure (Lei et al., 2017; Treynor et al., 2003), however, the validity of the three-factor construct is rarely verified. The revised three-factor model of RRS which excluded the item 14 is also considered to be appropriate which is similar with Korean sample (Shin et al., 2015).

Compared to the USA, Europe, Korean and Japan (Shin et al., 2015, Xavier et al., 2016; Lee \& Kim, 2014; Extremera \& Fernandez-Berrocal, 2006), the Cronbach's alpha of this study may be somewhat lower but acceptable according to standards of Baker et al (Lee \& Kim, 2014). Moreover, compared with college students samples (Lei et al., 2017), the application of RRS on adolescents samples showed higher Cronbach's alpha of the total scale. Except the brooding and reflection subscales, the depression scale also show accepted Cronbach's alpha which is consistent with the related Korean study. Therefore, the reliability of the total scale and three subscales (depression, brooding, and reflection) of the RRS were good to moderate (Evers et al., 2010). Standardized coefficient alpha is identical to the average correlation among $\mathrm{k}$ items adjusted by the Spearman-Brown formula, so increasing the number of items and revising items with low loading would yield an expected coefficient alpha.

Inter-subscale correlations are basically in agreement with previous research using the American (Stringars \& Goodman, 2013), Japanese (Hasegawa, 2013) and Korean (Shin et al., 2015) versions of the RRS in which the score of total RRS showed higher relationship with depression and brooding, but not reflection. The results of the correlation analysis showed that there was more significant correlation between brooding and depression than reflection. Because brooding is a repetitive negative thought (RNT), some research demonstrated that high levels of RNT were associated with higher negative affect (NA), such as depression and anxiety (Madian et al., 2018). Rumination, but not reflection, was associated with higher mean levels of negative affect (Moberly \& Watkins, 2008). Additionally, the current results are similar with those found in another Chinese study. In addition, the correlations between brooding and depression were stronger than those between reflection and depression, which was consistent with previous researches (Schoofs et al., 2010; Treynor et al., 2003). Because brooding as a behavior with negative inhibition, brooding was related to two emotion regulation strategies-suppression and acceptance, which positively associated with other types of suppression and negatively related to acceptance (Liverant et al., 2011; Laina et al., 2018).

Although female demonstrate higher levels of rumination and depression than male, it is unknown whether instruments used to measure rumination and depression have the same psychometric properties for female and male (Nolen-Hoeksema \& Girgus, 1994; Gunn \& Petersen, 1991). To examine this question, this study evaluated measurement invariance of the RRS by gender. The Chi-square test is easily affected by sample size, such that with an increase in sample size, even small differences may become significant. The CFI, GFI and 
TLI were used in the current study as the fit indices because they are not affected by the complexity of the model (Cheung \& Rensvold, 2002; Johnson et al., 2008). The previous researched have analysis the measurement invariance of two factor-model (GFI $=0.91$, CFI $=0.89$, TLI $=0.85$, RMSEA $=0.08)(50)$. Some researches also discussed the factorial invariance across different samples, such as different populations and different countries (Lucena-Santos et al., 2018; Arana \& Rice, 2017). According to the previous research, the result of the two-factor model suggested that the 10-item version of the RRS provided an assessment of psychometrically equivalent across gender (Whisman et al., 2018). While similar to previous studies, the current results of three-factor model found accepted gender equivalence, the measurement invariance across age was slightly inferior but accepted. This aim of this study were to demonstrate measurement invariance, and to identify and explore sources of heterogeneity (Prince, 2008). The results means that differences in RRS likely reflect valid differences in gender and age.

\section{Conclusion}

The results of the current study indicate good reliability and validity for application of the three-factor RRS in Chinese adolescents. Three-factor RRS is suitable for the research of depression and related response patterns, such as rumination and reflection in adolescents. However, some modifications are necessary in the depression subscale and other subscales.

Measurement equivalence across gender and age of the three-factor RRS was moderate to good, such that comparisons across gender and age groups are valid. If the difference significance test is carried out, the gender and age differences can be attributed to the differences of the subject variables, rather than the differences caused by the inequivalence of the questionnaire.

It is important to take into consideration some limitations of the current study. Firstly, we used a convenience sample of adolescent from two-provinces in Chinese, so the sample representation needs to be further improved. Secondly, this study relied on one-time self-reported RRS outcomes with no consideration of the potential variety of clinical statuses of the participants (Black \& Pössel, 2015).

\section{Author Contributions Statement}

Lijuan Liang managed the literature searches, participated in the collection and analysis of data and wrote the manuscript. Yung-Hsing Lee designed the study, participated in the collection and analysis of data, and revised the manuscript. All co-authors have approved the final manuscript.

\section{Conflicts of Interest}

The authors declare no conflicts of interest regarding the publication of this paper. 


\section{References}

Abramson, L. Y., Metalsky, G. I., \& Alloy, L. B. (1989). Hopelessness Depression: A Theory-Based Subtype of Depression. Psychological Bulletin, 96, 358-372. https://doi.org/10.1037//0033-295X.96.2.358

Aker, M., Harmer, C., \& Landrø, N. I. (2014). More Rumination and Less Effective Emotion Regulation in Previously Depressed Women with Preserved Executive Functions. BMC Psychiatry, 14, 334. https://doi.org/10.1186/s12888-014-0334-4

Arana, F. G., \& Rice, K. G. (2017). Cross-Cultural Validity of the Ruminative Responses Scale in Argentina and the United States. Assesment. https://doi.org/10.1177/1073191117729204

Bastin, M., Vanhalst, J., Raes, F., \& Bijttebier, P. (2018). Co-Brooding and Co-Reflection as Differential Predictors of Depressive Symptoms and Friendship Quality in Adolescents: Investigating the Moderating Role of Gender. Journal of Youth and Adolescence, 47, 1037-1051. https://doi.org/10.1007/s10964-017-0746-9

Black, S. W., \& Pössel, P. (2015). Integrating Beck's Cognitive Model and the Response Style Theory in an Adolescent Sample. Journal of Youth and Adolescence, 44, 195-210. https://doi.org/10.1007/s10964-013-0087-2

Broderick, P. C., \& Korteland, C. (2004). A Prospective Study of Rumination and Depression in Early Adolescence. Clinical Child Psychology and Psychiatry, 9, 383-394. https://doi.org/10.1177/1359104504043920

Butler, L. D., \& Nolen-Hoeksema, S. (1994). Gender Differences in Responses to Depressed Mood in a College Sample. Sex Roles, 30, 331-346. https://doi.org/10.1007/BF01420597

Campbell, T. S., Labelle, L. E., Bacon, S. L., Faris, P., \& Carlson, L. E. (2012). Impact of Mindfulness-Based Stress Reduction (MBSR) on Attention, Rumination and Resting Blood Pressure in Women with Cancer: A Waitlist-Controlled Study. Journal of Behavioral Medicine, 35, 262-271. https://doi.org/10.1007/s10865-011-9357-1

Cheung, G. W., \& Rensvold, R. B. (2002). Evaluating Goodness-of-Fit Indexes for Testing Measurement Invariance. Structural Equation Modeling: A Multidisciplinary Journal, 9, 233-255. https://doi.org/10.1207/S15328007SEM0902_5

Connolly, S. L., Hamilton, J. L., Stange, J. P. et al. (2015). Rumination and Overgeneral Autobiographical Memory in Adolescents: An Integration of Cognitive Vulnerabilities to Depression. Journal of Youth and Adolescence, 44, 806-818.

https://doi.org/10.1007/s10964-014-0090-2

Dickson, K. S., Ciesla, J. A., \& Zelic, K. (2017). Role of Executive Functioning in Adolescent Rumination and Depression. Cognitive Therapy and Research, 41, 62-72. https://doi.org/10.1007/s10608-016-9802-0

Evers, A., Sijtsma, K., Lucassen, W., \& Meijer, R. R. (2010). The Dutch Review Process for Evaluating the Quality of Psychological Tests: History, Procedure, and Results. International Journal of Testing, 10, 295-317. https://doi.org/10.1080/15305058.2010.518325

Extremera, N., \& Fernández-Berrocal, P. (2006). Validity and Reliability of Spanish Versions of the Ruminative Responses Scale-Short Form and the Distraction Responses Scale in a Sample of Spanish High School and College Students. Psychological Reports, 98, 141-150. https://doi.org/10.2466/pr0.98.1.141-150

Fornell, C., \& Larcker, D. F. (1981). Evaluating Structural Equation Models with Unobservable Variables and Measurement Error. Journal of Marketing Research, 18, 39-50. https://doi.org/10.1177/002224378101800104

Gotham, K. O., Siegle, G. J., Han, G. T. et al. (2018). Pupil Response to Social-Emotional 
Material Is Associated with Rumination and Depressive Symptoms in Adults with Autism Spectrum Disorder. PLoS ONE, 3, e0200340. https://doi.org/10.1371/journal.pone.0200340

Gunn, J., \& Petersen, A. C. (1991). Studying the Emergence of Depression and Depressive Symptoms during Adolescence. Journal of Youth \& Adolescence, 20, 115-119. https://doi.org/10.1007/BF01537603

Hasegawa, A. (2013). Translation and Internal Validation of the Japanese Version of the Ruminative Responses Scale. Psychological Reports, 112, 716-726. https://doi.org/10.2466/02.08.PR0.112.3.716-726

Johnson, E. C., Meade, A. W., \& Braddy, P. W. (2008). Power and Sensitivity of Alternative Fit Indices in Tests of Measurement Invariance. Journal of Applied Psychology, 93, 568-592. https://doi.org/10.1037/0021-9010.93.3.568

Jos, P. E., \& Weir, K. F. (2013). How Is Anxiety Involved in the Longitudinal Relationship between Brooding Rumination and Depressive Symptoms in Adolescents? Journal of Youth and Adolescence, 42, 1210-1222. https://doi.org/10.1007/s10964-012-9891-3

Kessler, R. C., Avenevoli, S., \& Merikangas, K. R. (2001). Mood Disorders in Children and Adolescents: An Epidemiologic Perspective. Biological Psychiatry, 49, 1002-1014. https://doi.org/10.1016/S0006-3223(01)01129-5

Kline, R. B. (2005). Principles and Practice of Structural Equation Modeling (2nd ed., pp. 365-386). New York: Guilford.

Lee, S., \& Kim, W. (2014). Cross-Cultural Adaptation, Reliability, and Validity of the Revised Korean Version of Ruminative Response Scale. Psychiatry Investigation, 11, 59-64. https://doi.org/10.4306/pi.2014.11.1.59

Lei, X., Zhong, M., Liu, Y. et al. (2017). Psychometric Properties of the 10-Item Ruminative Response Scale in Chinese University Students. BMC Psychiatry, 17, 152.

https://doi.org/10.1186/s12888-017-1318-y

LeMoult, J., Humphreys, K. L., King, L. S. et al. (2019). Associations among Early Life Stress, Rumination, Symptoms of Psychopathology, and Sex in Youth in the Early Stages of Puberty: A Moderated Mediation Analysis. Journal of Abnormal Child Psychology, 47, 199-207. https://doi.org/10.1007/s10802-018-0430-x

Liverant, G. I., Kamholz, B. W., Sloan, D. M., \& Brown, T. A. (2011). Rumination in Clinical Depression: A Type of Emotional Suppression? Cognitive Therapy and Research, 35, 253-265. https://doi.org/10.1007/s10608-010-9304-4

Lucena-Santos, P., Pinto-Gouveia, J., Carvalho, S. A., \& da Silva Oliveira, M. (2018). Is the Widely Used Two-Factor Structure of the Ruminative Responses Scale Invariant across Different Samples of Women? Psychological Psychotherapy, 91, 398-416. https://doi.org/10.1111/papt.12168

Madian, N., Bredemeier, K., Heller, W., Miller, G. A., \& Warren, S. L. (2018). Repetitive Negative Thought and Executive Dysfunction: An Interactive Pathway to Emotional Distress. Cognitive Therapy and Research, 43, 464-480.

McMurrich, S. L., \& Johnson, S. L. (2008). Dispositional Rumination in Individuals with a Depression History. Cognitive Therapy and Research, 32, 542-553. https://doi.org/10.1007/s10608-006-9093-y

Moberly, N. J., \& Watkins, E. R. (2008). Ruminative Self-Focus and Negative Affect: An Experience Sampling Study. Journal of Abnormal Psychology, 117, 314-323. https://doi.org/10.1037/0021-843X.117.2.314

Nolen-Hoecksema, S., Girgus, J. S., \& Seligman, M. E. (1992). Predictors and Consequences of Childhood Depressive Symptoms: A 5-Year Longitudinal Study. Journal of Abnormal Psychology, 101, 405-422. https://doi.org/10.1037/0021-843X.101.3.405 
Nolen-Hoeksema, S. (1987). Sex Differences in Unipolar Depression: Evidence and Theory. Psychological Bulletin, 101, 259-282.

Nolen-Hoeksema, S. (1991). Responses to Depression and Their Effects on the Duration of Depressive Episodes. Journal of Abnormal Psychology, 100, 569-582.

Nolen-Hoeksema, S., \& Girgus, J. S. (1994). The Emergence of Gender Differences in Depression during Adolescence. Psychological Bulletin, 115, 424-443. https://doi.org/10.1037/0033-2909.115.3.424

Paredes, P. P., \& Zumalde, E. C. (2015). A Test of the Vulnerability-Stress Model with Brooding and Reflection to Explain Depressive Symptoms in Adolescence. Journal of Youth and Adolescence, 44, 860-869. https://doi.org/10.1007/s10964-014-0148-1

Prince, M. (2008). Measurement Validity in Cross-Cultural Comparative Research. Epidemiologia E Psichiatria Sociale, 17, 211-220. https://doi.org/10.1017/S1121189X00001305

Sarkisian, K. L., Van Hulle, C. A., \& Goldsmith, H. (2019). Brooding, Inattention, and Impulsivity as Predictors of Adolescent Suicidal Ideation. Journal of Abnormal Child Psychology, 47, 333-344. https://doi.org/10.1007/s10802-018-0435-5

Schoofs, H., Heamans, D., \& Raes, F. (2010). Brooding and Reflection as Subtypes of Rumination: Evidence from Confirmatory Factor Analysis in Nonclinical Samples Using the Dutch Ruminative Responses Scale. Journal of Psychopathology and Behavioral Assessment, 32, 609-617. https://doi.org/10.1007/s10862-010-9182-9

Shin, K. M., Cho, S. M., \& Kim, K. H. (2015). A Validation Study of the Korean Ruminative Response Scale in Korean Adolescents. Psychiatry Investigation, 12, 508-515. https://doi.org/10.4306/pi.2015.12.4.508

Stringars, A., \& Goodman, R. (2013). The Value of Measuring Impact alongside Symptoms in Children and Adolescents: A Longitudinal Assessment in a Community Sample. Journal of Abnormal Child Psychology, 41, 1109-1120.

https://doi.org/10.1007/s10802-013-9744-x

Thomsen, D. K., Jensen, A. B., Jensen, T. et al. (2013). Rumination, Reflection and Distress: An 8-Month Prospective Study of Colon-Cancer Patients. Cognitive Therapy and Research, 37, 1262-1268. https://doi.org/10.1007/s10608-013-9556-x

Thomsen, D. K., Schnieber, A., \& Olesen, M. H. (2011). Rumination Is Associated with the Phenomenal Characteristics of Autobiographical Memories and Future Scenarios. Memory, 19, 574-584. https://doi.org/10.1080/09658211.2011.591533

Topper, M., Emmelkamp, P. M., Watkins, E., \& Ehring, T. (2014). Development and Assessment of Brief Versions of the Penn State Worry Questionnaire and the Ruminative Response Scale. British Journal of Clinical Psychology, 53, 402-421. https://doi.org/10.1111/bjc.12052

Treynor, W., Gonzalez, R., \& Nolen-Hoeksema, S. (2003). Rumination Reconsidered: A Psychometric Analysis. Cognitive Therapy and Research, 27, 247-259. https://doi.org/10.1023/A:1023910315561

Tsaousis, I., \& Kazi, S. (2013). Factorial Invariance and Latent Mean Differences of Scores on Trait Emotional Intelligence across Gender and Age. Personality \& Individual Differences, 54, 169-173. https://doi.org/10.1016/j.paid.2012.08.016

Whisman, M. A., Miranda, R., Fresco, D. M., Heimberg, R. G., Jeglic, E. L., \& Weinstock, L. M. (2018). Measurement Invariance of the Ruminative Responses Scale across Gender. Assessment. https://doi.org/10.1177/1073191118774131

Wilkinson, P. O., \& Goodyer, I. M. (2008). The Effects of Cognitive-Behavioural Therapy on Mood-Related Ruminative Response Style in Depressed Adolescents. Child and 
Adolescent Psychiatry and Mental Health, 2, 3. https://doi.org/10.1186/1753-2000-2-3

Wilkinson, P. O., Croudace, T. J., \& Goodyer, I. M. (2013). Rumination, Anxiety, Depressive Symptoms and Subsequent Depression in Adolescents at Risk for Psychopathology: A Longitudinal Cohort Study. BMC Psychiatry, 13, 250.

https://doi.org/10.1186/1471-244X-13-250

Xavier, A., Cunha, M., \& Pinto-Gouveia, J. (2016). Rumination in Adolescence: The Distinctive Impact of Brooding and Reflection on Psychopathology. The Spanish Journal of Psychology, 19, E37. https://doi.org/10.1017/sjp.2016.41 